\title{
Effects of Drought Frequency on Growth Performance and Transpiration of Young Black Locust (Robinia pseudoacacia L.)
}

\author{
Dario Mantovani, ${ }^{1,2}$ Maik Veste, ${ }^{3}$ and Dirk Freese ${ }^{2}$ \\ ${ }^{1}$ International Graduate School, Brandenburg University of Technology Cottbus-Senftenberg, Konrad-Wachsmann-Allee 6, \\ 03046 Cottbus, Germany \\ ${ }^{2}$ Chair of Soil Protection and Recultivation, Brandenburg University of Technology Cottbus-Senftenberg, Konrad-Wachsmann-Allee 6, \\ 03046 Cottbus, Germany \\ ${ }^{3}$ Centre for Energy Technology Brandenburg e.V. (CEBra), Friedlieb-Runge-Straße 3, 03046 Cottbus, Germany
}

Correspondence should be addressed to Dario Mantovani; mantdar2@gmail.com

Received 19 November 2013; Revised 28 January 2014; Accepted 28 January 2014; Published 17 March 2014

Academic Editor: Kihachiro Kikuzawa

Copyright (C) 2014 Dario Mantovani et al. This is an open access article distributed under the Creative Commons Attribution License, which permits unrestricted use, distribution, and reproduction in any medium, provided the original work is properly cited.

\begin{abstract}
Black locust (Robinia pseudoacacia L.) is a drought-tolerant fast growing tree, which could be an alternative to the more common tree species used in short-rotation coppice on marginal land. The plasticity of black locust in the form of ecophysiological and morphological adaptations to drought is an important precondition for its successful growth in such areas. However, adaptation to drought stress is detrimental to primary production. Furthermore, the soil water availability condition of the initial stage of development may have an impact on the tree resilience. We aimed to investigate the effect of drought stress applied during the resprouting on the drought tolerance of the plant, by examining the black locust growth patterns. We exposed young trees in lysimeters to different cycles of drought. The drought memory affected the plant growth performance and its drought tolerance: the plants resprouting under drought conditions were more drought tolerant than the well-watered ones. Black locust tolerates drastic soil water availability variations without altering its water use efficiency $\left(2.57 \mathrm{~g} \mathrm{~L}^{-1}\right)$, evaluated under drought stress. Due to its constant water use efficiency and the high phenotypic plasticity, black locust could become an important species to be cultivated on marginal land.
\end{abstract}

\section{Introduction}

Summer drought, as observed during extreme events in Central Europe in 2003 [1], is one of the major abiotic stress factors that limit plant growth and have drastic effects on the ecosystem productivity. The ongoing climate change amplifies the interannual climate variability and changes the seasonal distribution of rainfall in Central Europe [2]. Within Central Europe particularly the southern parts of Brandenburg and Poland will be highly vulnerable to climate change and a decrease in summer precipitation is forecasted. Consequently, drought periods during the growth season are to be expected [3]. In this region the reduced soil water availability (SWA), in combination with sandy soils, has led to negative effects on the productivity of the ecosystem [4]. An integrated concept of active species selection and an appropriate management of tree stands could mitigate the effect of the climatic stress to a certain extent. Therefore, it is important to assess the plasticity of the species to drought stress by understanding the plant response in terms of water consumption, growth performance, and production [5]. This is particularly important for short-rotation coppice (SRC) systems, where the primary production is driven mainly by the SWA [6,7]. Black locust (Robinia pseudoacacia L.), as a drought tolerant species suitable for SRC, can be grown even on reclaimed post-mining sites, where the edaphic conditions are extreme [8]. Various studies emphasize the black locust morphological and ecophysiological adaptations in coping with long-term drought stress [9-11]. Hence, the ecological stress memory, defined by Walter et al. [12] as any response of a single plant after a stress experience, which improves the response of the same plant towards future stress experiences, 
could be an important factor when evaluating the drought stress tolerance of the species. Depending on the drought stress severity, a reduction of the primary production due to these morphological and physiological adjustments is to be expected [13-15]. Stomatal closure is a typical temporary reaction to drought stress, leading to a reduced $\mathrm{CO}_{2}$ uptake and finally influencing carbon budgets and growth performances [16, 17]. Besides physiological adjustments, drought stress occurring during the tree development induces morphological adaptations from the roots to the crown, which will characterize the hydraulic architecture of the tree [1823]. As a consequence the transpiration of the plant will be influenced, along with its tolerance to drought stress [18-20]. Hence the recovering process after drought stress in terms of growth increment could be affected by the SWA at the initial stage of resprouting. In spite of the importance of this topic for coppicing practices, up to this date there is still a considerable informational gap: the effect of the drought occurring during the resprouting period on the drought tolerance, biomass production, and water use under drought stress has not been investigated. In our study, we aimed to assess the impact of drought cycles, applied during the resprouting phase on the drought resilience of black locust trees. We defined the physiological conditions in terms of plant water status at which the growth performance is compromised and analyzed the influence of drought applied during the resprouting phase on the hydraulic architecture of the tree, evaluating the relation between root system and the total transpiring surface. The effect of the different root weight: leaf area ratio was evaluated by analyzing (i) growth performance, (ii) transpiration rate, (iii) aboveground biomass production, and (iv) the water use efficiency under cyclic drought stress. The information gathered enlightened the importance of black locust as an appropriate tree for marginal land and the strong implication that the SWA during the resprouting phase has on the later drought tolerance and productivity of the species.

\section{Material and Methods}

2.1. Plants and Drought Stress Treatment. The study was carried out with three-year-old black locust trees in a lysimeter experiment, under a light transmissive rain-out shelter, arranged at the Brandenburg University of Technology Cottbus-Senftenberg. The water was supplied solely by an automatic irrigation system. The plant material was collected from a short-rotation plantation in the postmining area of Welzow-Süd, Brandenburg, Germany (N $51^{\circ} 36^{\prime} 14^{\prime \prime}$, E $\left.14^{\circ} 19^{\prime} 51^{\prime \prime}\right)$, approximately $25 \mathrm{~km}$ south from the lysimeter facility. The climate at the collection site and at the lysimeter facility is comparable. It is a transition from the Atlantic to the continental climate, with mean annual rainfall of $556 \mathrm{~mm}$ and mean annual temperature of $9.3^{\circ} \mathrm{C}(1951-2003$, Deutscher Wetterdienst). During the experiment, the highest air temperature in Cottbus was reached in August 2012 with more than $36.5^{\circ} \mathrm{C}$. The monthly mean temperature was $+0.7^{\circ} \mathrm{C}$ above the long-term average, while the early summer was $-0.5^{\circ} \mathrm{C}$ (June) and $-0.3^{\circ} \mathrm{C}$ (July) colder than the average.
However, extreme conditions with air temperatures above $30^{\circ} \mathrm{C}$ and even $35^{\circ} \mathrm{C}$ as observed in 2012 are common in Brandenburg. All the selected trees presented a comparable crown architecture, with three main branches (mean radius of $10.6 \pm 1.9 \mathrm{~cm}$ ) connected to the trunk (mean radius of $13.4 \pm 1.9 \mathrm{~cm}$, height approx. $30 \mathrm{~cm}$ ). At the beginning of the experiment, all the primary branches were cut back at $10 \mathrm{~cm}$ from the trunk. After a period of establishment (March 20 to June 1, 2012), during which the plants were well watered, the drought cycle experiment started on June 1 until October 11 with two treatments: short-term drought stress (STS) and long-term drought stress (LTS), each executed in three replicas $(n=3)$. In our context we defined drought stress as a condition where the mean soil water content $(\theta)$ was maintained at values of $7 \%$, which is the value at which the growth rate drastically decreases to values close to zero. The well-watered condition instead corresponded to the hydrostatic state of the lysimeter, where the mean of the $\theta$ was set at $20 \%$, with full availability of water. Since all treatments started developing new leaves during the last week of May, we considered the resprouting phase the period from the 23rd to the 26th week of the year (WOY). The cycling of drought and full availability of water was scheduled as follows: the LTS plants experienced drought conditions throughout the four weeks of the resprouting period. Instead, the STS plants were exposed only to one week of drought (24th WOY) during the same period. After the resprouting phase, three weeks of well-watered conditions followed for both treatments. From the 30th WOY on both treatments were exposed to drought stress for two weeks. From the 33 rd WOY until the end of the experiment (41st WOY), the STS plants were subjected to short-term drought stress (one week of drought and two well-watered ones), while the LTS plants were subjected to long-term drought stress (two weeks of drought stress, followed by one week of well-watered condition).

2.2. Lysimeter and Soil Water Status. In order to control the SWA and to calculate the water budget, the plants were grown in lysimeters $(50 \mathrm{~cm}$ diameter, $50 \mathrm{~cm}$ height) under a light transmissive rain-out shelter [11]. The daily transpiration was calculated by the difference between the measured irrigation and the sum of the estimated daily water storage variation and the leachate collected. Evaporation from bare soil was minimized by covering the soil with a double leaflet. To facilitate the infiltration rate, the sandy loam soil column was filled at bulk density $1.3 \mathrm{~kg} \mathrm{~m}^{-3}$. The soil, relatively low in organic carbon $(1.3 \%)$ and total nitrogen $(0.08 \%)$, presented the oxalate-extractable $\mathrm{Al}, \mathrm{Fe}$, and $\mathrm{Mn}$ content values of $0.65,1.53$, and $0.08 \mathrm{mg} \mathrm{g}^{-1}$, respectively. The irrigation system was automatically controlled by a data logger (GP1, Delta-T Devices, Cambridge, UK) and the water was dispensed from four drippers per lysimeter. The volume of water was supplied in relation to the volumetric soil water content, measured at $20 \mathrm{~cm}$ depth by a frequency domain reflectometry probe (SM-200, Soil Moisture Sensor Delta-T Devices, Cambridge, UK). To evaluate the storage variation of the weekly water budget, the $\theta$ was measured at four depths $(10,20,30$, and 


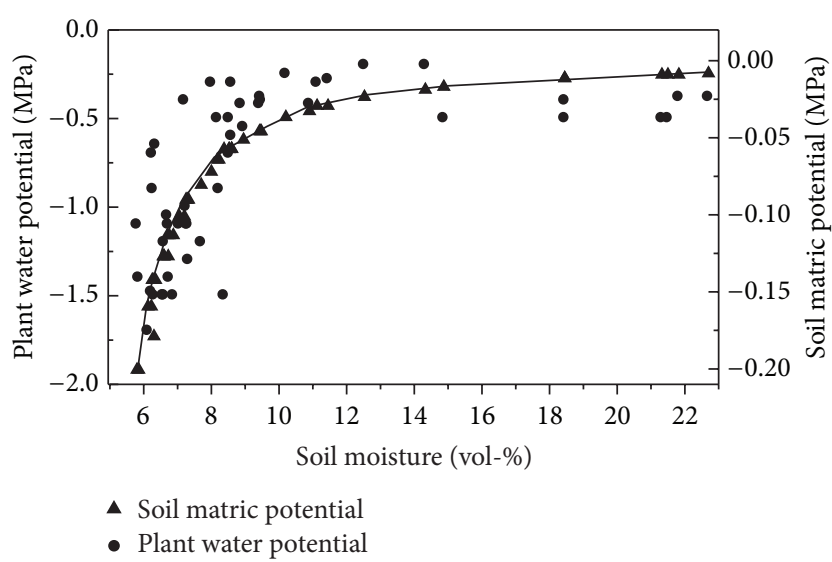

FIGURE 1: Predawn leaf water potential and soil matric potential in relation to the soil moisture and soil water retention curve.

$40 \mathrm{~cm}$ ) with a profile probe (PR2/4w-02, Delta-T Devices, Cambridge, UK). The climatic variables air temperature and relative humidity were monitored on an hourly basis by using thermistor-hygrometers (HC2-S, Rotronic AG, Bassersdorf, Germany). The vapor pressure deficit (VPD) values were calculated for the daytime by the air temperature and relative humidity recorded from 09:00 HR to 18:00 HR local summer time.

2.3. Leaf Water Potential. We linked the physiological condition of the trees in terms of plant water status to the growth rate by measuring the leaf water potential $\left(\Psi_{L}\right)$ at different soil moisture conditions. The leaf water potential was measured at predawn time on three fully developed leaves for each tree by using the Scholander pressure chamber (Plant Water Status Console 3000, Soilmoisture Inc., Santa Barbara, CA, USA) after Veste et al. [24]. The water potential of the distal part of the rachis, approximately $10 \mathrm{~cm}$ completed with leaflets, was measured immediately after the excision. We linked the $\Psi_{L}$ to the SWA, by using the soil water retention curve of the lysimeter soil column after Mantovani et al. [11] to convert the soil $\theta$ values read by the sensors into soil matric potential $\left(\Psi_{S}\right)$ values $(\mathrm{MPa})$ (Figure 1$)$. The correlations between $\Psi_{S}$ and $\Psi_{L}$ and between $\Psi_{L}$ and $\theta$ are significant, with a coefficient of correlation of -0.749 and -0.757 , respectively (Figure 1).

Having this way both variables expressed in the same unit $(\mathrm{MPa})$, we used the linear relation $\left(\Psi_{L}=90.13 * \Psi_{S}, r^{2}=\right.$ 0.86 ) described in Figure 2, to set the indirect plant-based irrigation control and monitoring system.

2.4. Growth Rate and Biomass Production. The response to drought stress in terms of growth increment throughout the vegetation period was evaluated on a different time scale by using dendrometers (DD-S, Ecomatik, Dachau, Germany) and a caliper. The dendrometers were installed around the trunk of each plant at $20 \mathrm{~cm}$ height from the soil and the radial variations were recorded daily at dawn time 05:00 $\mathrm{HR}$, to avoid bias measurements due to excessive trunk shrinkage. To minimize the effect of the different initial trunk

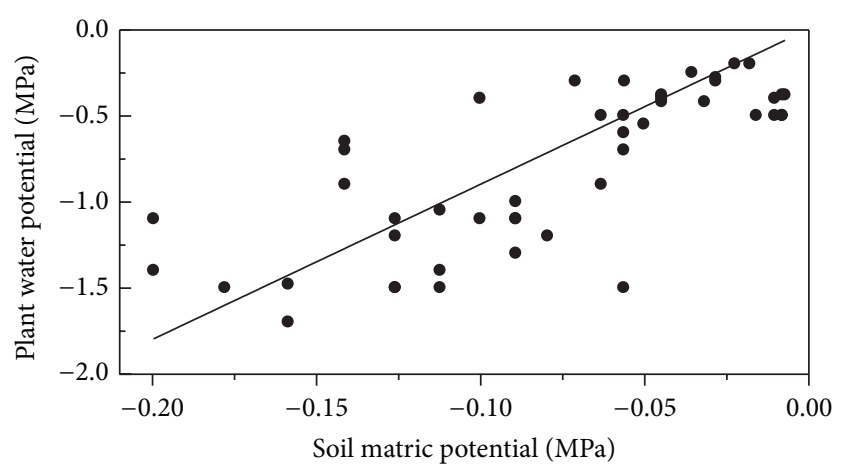

FIGURE 2: Relation between the measured predawn leaf water potential and the calculated soil matric potential.

radii, the data series was compared in relative terms, as a percentage of the growth. The monthly growth rate instead was evaluated by measuring the trunk radius at $25 \mathrm{~cm}$ height from the soil with the caliper and the main branch at approximately $10 \mathrm{~cm}$ from the trunk. Also the monthly growth rate is expressed as a percentage of the growth. Furthermore, the data series is plotted after normalization. The biomass production was measured at the end of the vegetation period. The total aboveground biomass (secondary branches and leaves) was harvested before the defoliation (October 11, 2012) and oven-dried separately at $65^{\circ} \mathrm{C}$ until a constant dry weight was reached. The gravimetric increment of the trunk and the primary branches was estimated by multiplying the seasonal volumetric increment recorded throughout the experiment, making use of the calculated specific weight of the black locust dry wood $\left(0.76 \mathrm{~g} \mathrm{~cm}^{-3}\right)$ estimated from the secondary branches. The water use efficiency (WUE) under different drought stress durations was calculated after the harvest by the ratio between the dry total aboveground biomass produced during the vegetation period and the water used. On the other hand, the economical water use efficiency (EWUE) under different drought stress durations was calculated considering only the dry aboveground wood production.

2.5. Leaf Area and Root Vertical Distribution. The total leaf area $\left(\mathrm{m}^{2}\right)$ for a single tree was calculated at the harvest, by multiplying the black locust specific leaf area $\left(\mathrm{g} \mathrm{m}^{-2}\right)$ by the weight of the total dry leaves collected from each tree. The specific leaf area was calculated from the ratio between the measured area of 10 fully developed single leaves for each tree and their single dry weight.

In order to evaluate the vertical spatial distribution of the root weight, without the stump, root sampling was performed at $5 \mathrm{~cm}, 20 \mathrm{~cm}$, and $40 \mathrm{~cm}$ soil depth at the end of the experiment (October 11, 2012). We used six steal rings of known volume $(5 \mathrm{~cm}$ radius $\times 10 \mathrm{~cm}$ height $)$ at each soil depth. To homogenize the operation, three samples were collected at $10 \mathrm{~cm}$ from the center of the lysimeter and three samples at $10 \mathrm{~cm}$ from the lysimeter wall for each layer. All the roots contained in the rings were separated and the soil was removed from the roots with a brush. The roots were 


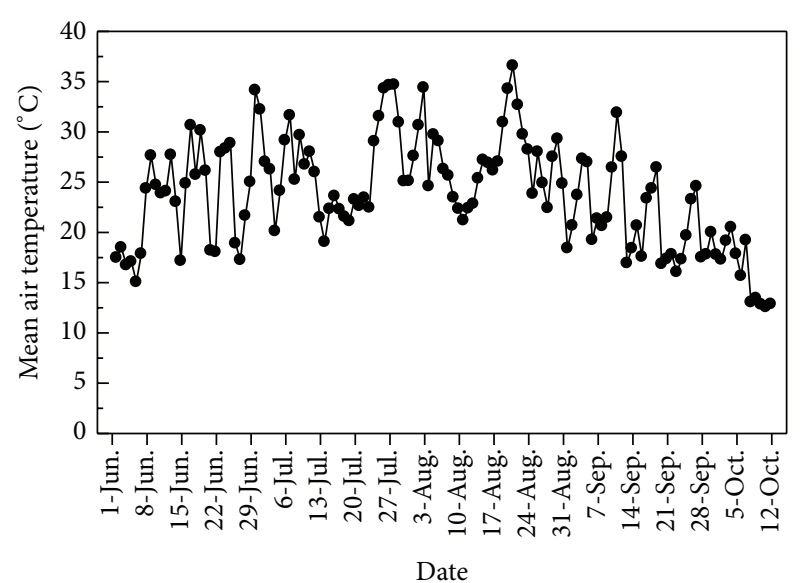

(a)

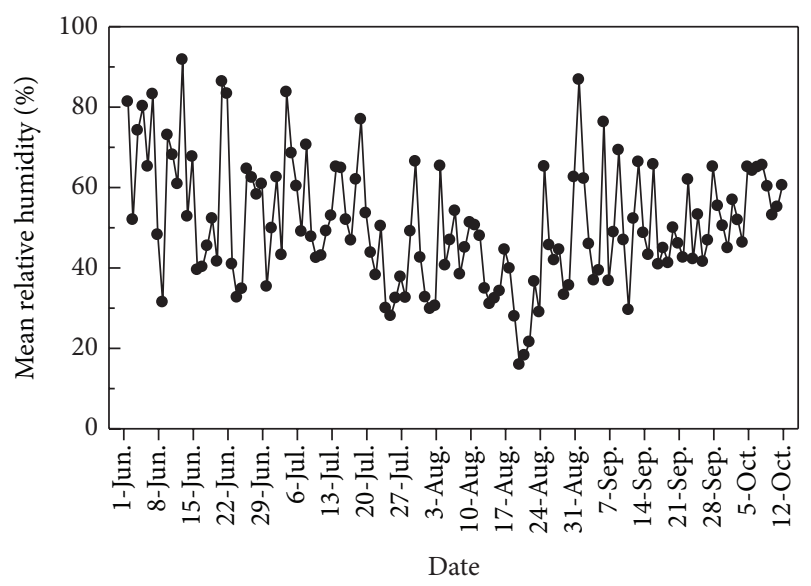

(b)

FIGURE 3: Mean of the daily temperature and relative humidity measured on a hourly basis, calculated from 09:00 HR to 18:00 HR, recorded throughout the vegetation period.

washed carefully in a dish of water to remove any residual soil. Subsequently, they were oven-dried at $65^{\circ} \mathrm{C}$ till steady weight. The total root biomass ( $\mathrm{g}$ ) for each depth was determined by weighing the roots of each sample and multiplying the mean of the root weight density $\left(\mathrm{g} \mathrm{cm}^{3}\right)$ by the soil volume of each depth, amounting to $32773 \mathrm{~cm}^{3}$.

2.6. Statistical Analysis. The nonparametric Spearman rho correlation $(P<0.05)$ was applied to correlate (i) the weekly water use, growth rate, and the VPD, (ii) the $\Psi_{S}$ and the $\Psi_{L}$, and (iii) the $\Psi_{L}$ and the $\theta$. The non-parametric analysis Mann-Whitney $U$ test $(P<0.05)$ was performed to compare (i) the mean weekly growth rate, (ii) the cumulative water use, (iii) the trunk and branch radial increments, (iv) the aboveground biomass production, (v) the root weight vertical distribution, (vi) the total leaf area, and (vii) the WUE and the EWUE under drought stress, between and within the treatments. All the analyses were executed by using the IBM SPSS version 21 (SPSS Inc, Chicago, IL, USA).

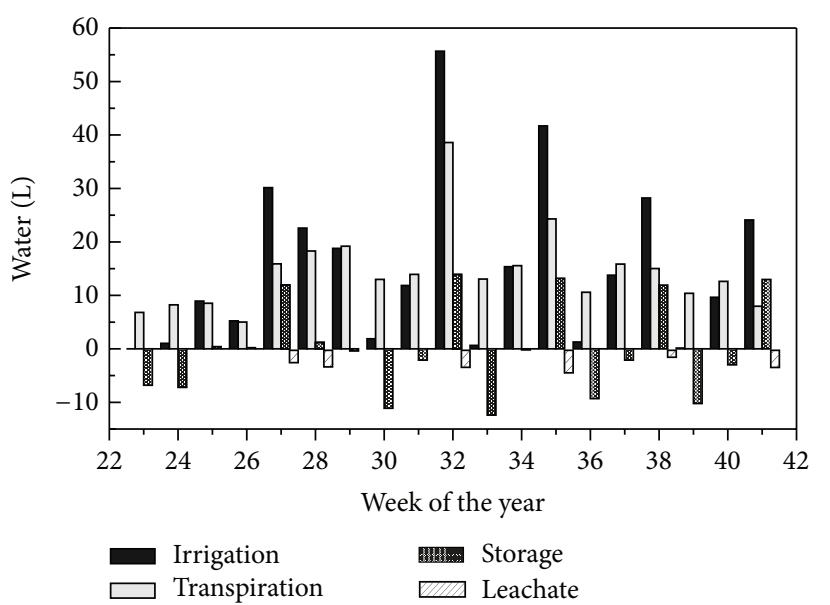

(a)

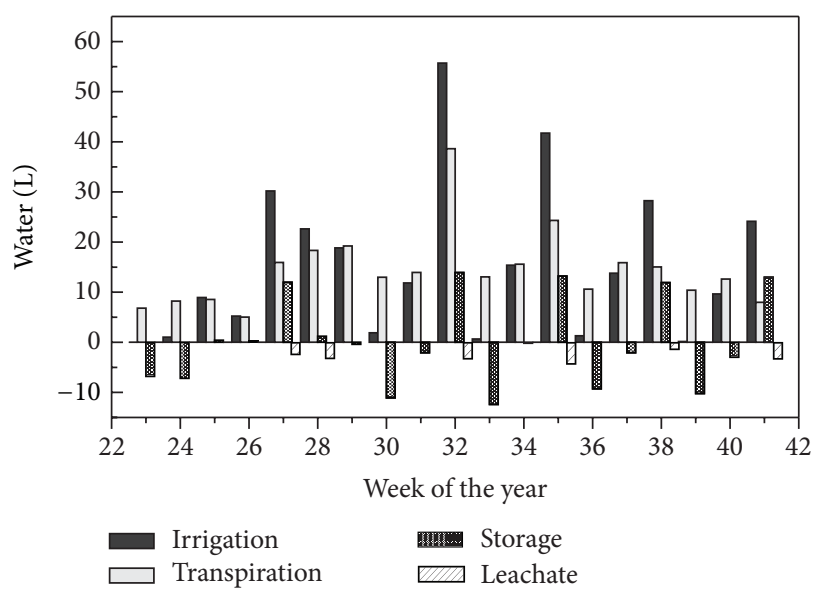

(b)

FIGURE 4: Mean of the weekly experimental water balance calculated throughout the vegetation period.

\section{Results}

3.1. Water Use. The mean of the daily air temperature and relative humidity, recorded during the vegetation period, is shown in Figure 3. During the vegetation period, for 18 days the mean of the daily temperature was above $30^{\circ} \mathrm{C}$, and 7 days above $34^{\circ} \mathrm{C}$, with a peak of $36.5^{\circ} \mathrm{C}$ in August. The last day with a temperature $30^{\circ} \mathrm{C}$ was September 10. After that the temperature slowly decreased till reaching the minimum values of $12.5^{\circ} \mathrm{C}$ at the end of the experiment.

In order to calculate the weekly transpiration, the experimental water balance was performed (Figure 4). During the periods when the plants were well watered, the leachate was minimized by maintaining the soil column at the hydrostatic state, in order to avoid excessive soil particle translocation. During the transition phase from well-watered to drought condition, the irrigation was stopped and the plants used the water stored into the soil, till the predefined value of $7 \%$ was reached. On the other hand, during the transition phase from drought condition to well watered, the irrigation supplied 


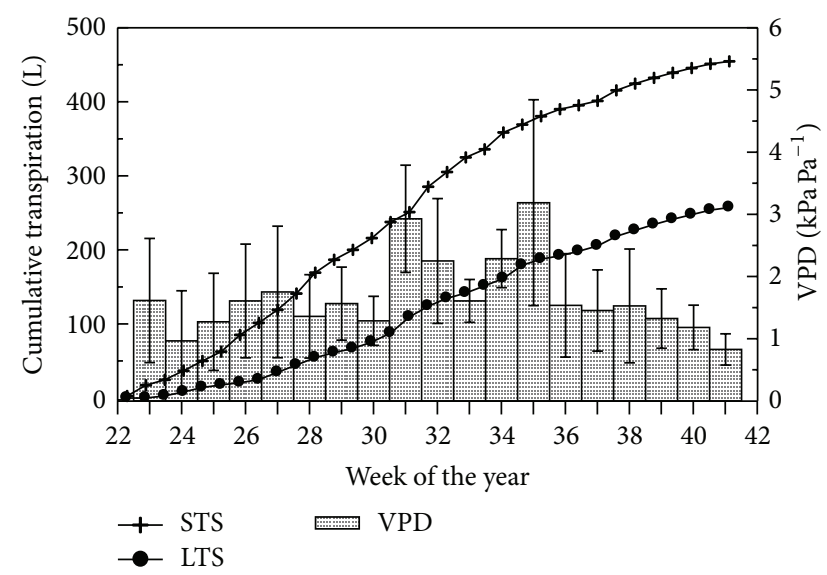

(a)

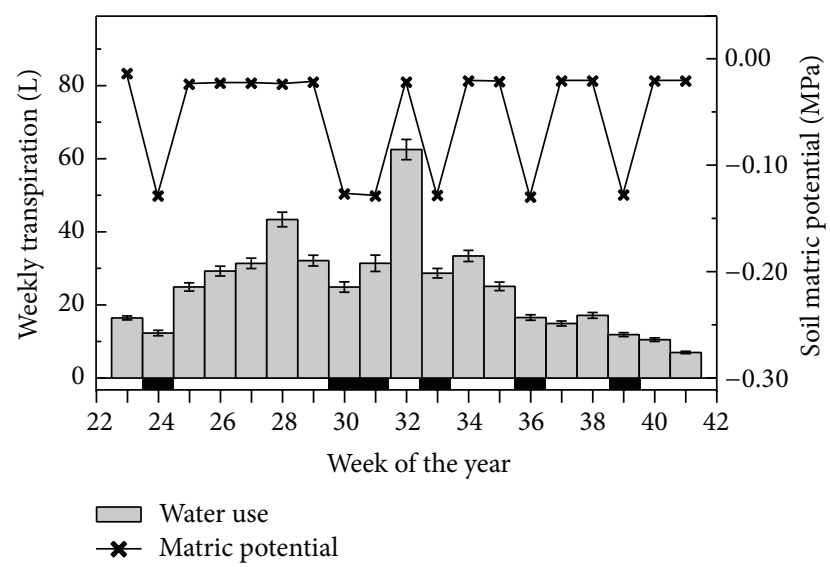

(b)

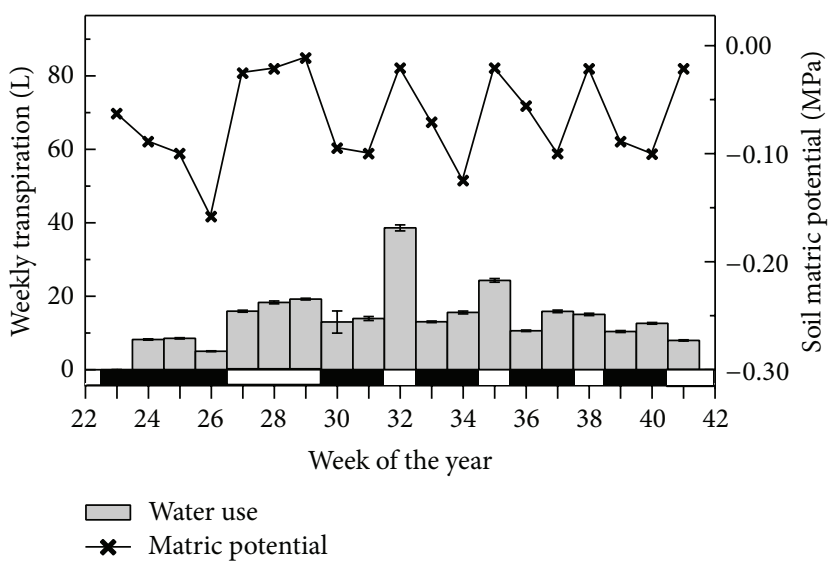

(c)

Figure 5: (a) Mean and standard deviation of the weekly vapor pressure deficit and cumulative water use, (b) short-term stress treatment mean and standard deviation of the weekly water use and mean of the soil matric potential, and (c) long-term stress treatment mean and standard deviation of the weekly water use and mean of the soil matric potential. ${ }^{*}$ Drought stress periods are marked with a black rectangle beneath the bars.

additional water to recharge the storage till the predefined value of $20 \%$ was reached.

The mean transpiration from the LTS treatment during the vegetation period amounted to $260.0 \pm 7.6 \mathrm{~L}$, corresponding to $57 \%$ of the water used by the STS treatment $(456.8 \pm 25.3 \mathrm{~L})$ (Figure 5(a)). The mean of the weekly water use of the STS treatment was more affected by the mean of the weekly VPD as compared to the LTS treatment. The correlation was significant for both treatments, with coefficients of 0.680 and 0.499 for STS and LTS, respectively. From the analysis of the weekly water balance, we can visualize the different plant responses to the SWA variation in terms of water use (Figures 5(b) and 5(c)). During the first four weeks of our investigation (WOY 23-26), the LTS water use was only $26 \%$, compared to the STS. For the following three weeks (WOY 27, 28, and 29) the trees were already differentiated and the LTS used only $50 \%$ of the water used by the STS plants. When imposing the drought regime (WOY 30 and 31), both treatments reduced their water use. However, the STS still transpired 52\% more water than the LTS.
After the drought period (WOY 32), the plants of both treatments recovered quickly and the water use rose up by $50 \%$ and $74 \%$ for the STS and LTS, respectively. During WOY 33 both treatments drastically dropped their water consumption to values comparable to the values recorded during the previous phase of drought stress (WOY 31). The STS trees did not recover their functions fully, since the water consumption increased only by $14 \%$ (WOY 34 ) and was followed by a further decrease of $25 \%$ (WOY 35). During the subsequent stress period (WOY 36) defoliation started and the water consumption was reduced by $34 \%$, not to recover anymore, till it reached the minimum mean weekly value of $6.9 \pm 0.3 \mathrm{~L}$ during the last week of the investigation (WOY 41). The LTS instead did not change its water consumption substantially during the last two drought stress cycles, till reaching the minimum mean weekly value of $7.9 \mathrm{~L}$.

3.2. Growth. The correlation between the mean weekly relative trunk radial increment and the mean weekly $\Psi_{L}$ was 


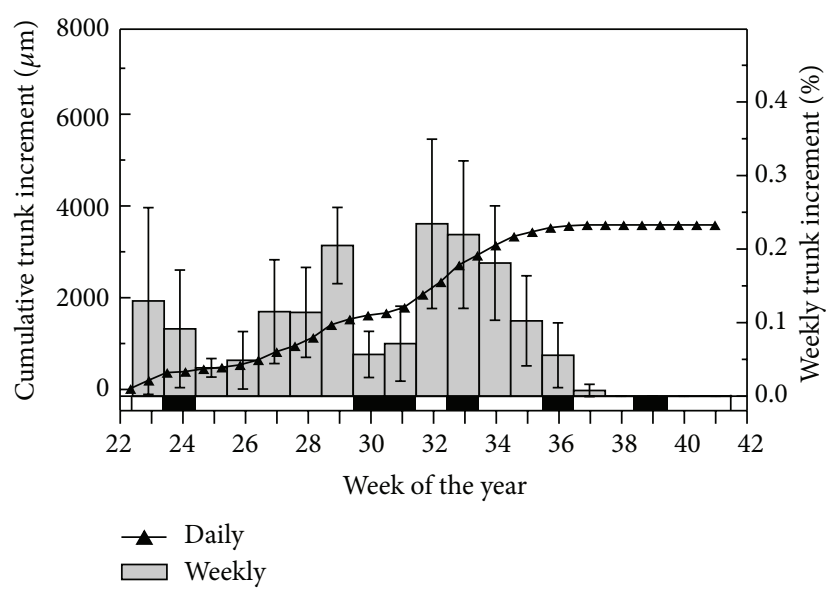

(a)

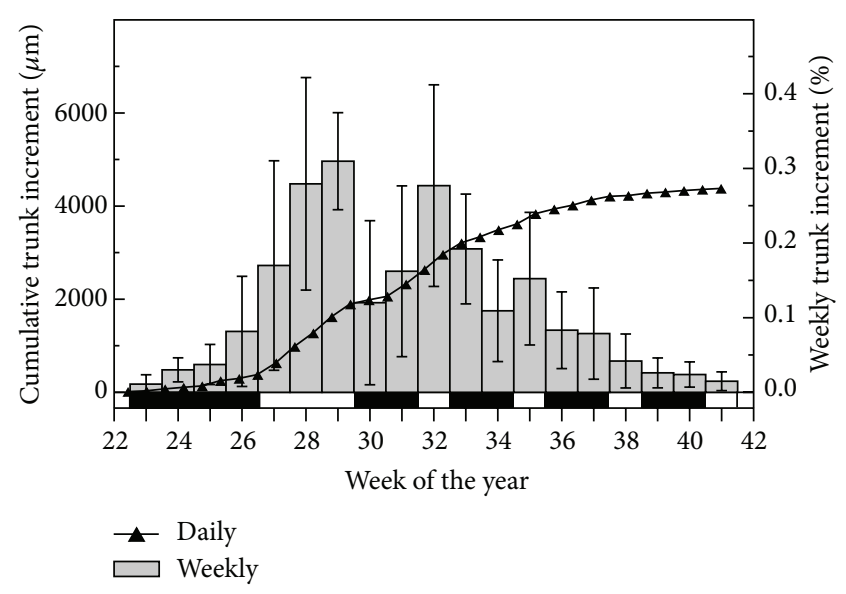

(b)

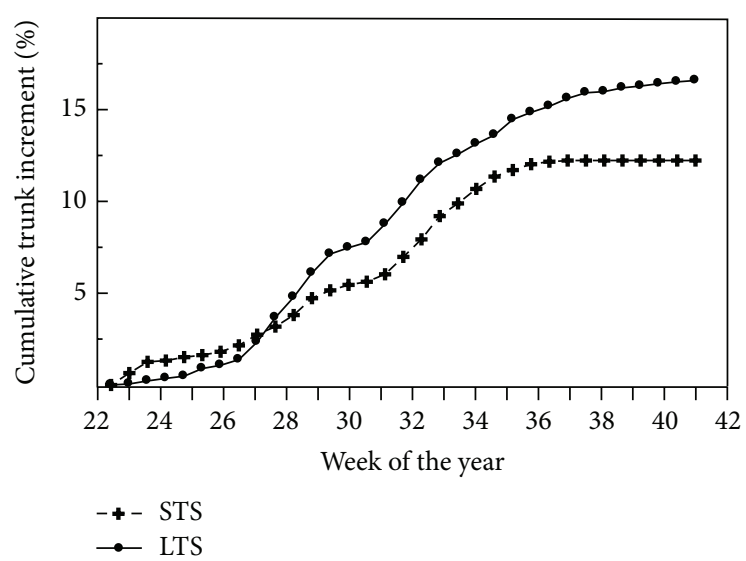

(c)

Figure 6: Mean daily trunk increment and mean standard variation of the weekly relative trunk increment: (a) short-term stress, (b) longterm stress, and (c) mean cumulative relative trunk increase of STS and LTS.

not significant. The STS treatment decreased the trunk radial increment by $58 \%$ after WOY 24 and only recovered slowly before the following drought stress (WOY 28) (Figure 6(a)). The mean LTS radial increment (Figure 6(b)) after the stress (WOY 23-26) on the other hand increased dramatically by $119 \%$ and kept on increasing for the following three weeks (WOY 27, 28, and 29). After one week of stress (WOY 30), we had a drastic reduction of the mean weekly radial increment of $72 \%$ and $61 \%$ for the STS and LTS, respectively. However, during the second week of stress (WOY 31), where the mean weekly VPD reached values of $2.93 \mathrm{kPa} \mathrm{Pa}^{-1}$, the mean trunk radial increment increased by $26 \%$ and $36 \%$ for the STS and LTS, respectively. By rewatering (WOY 32), the plants of both treatments recovered. The mean of the STS trunk radial increment increased by $60 \%$, while the LTS increased by $48 \%$. During the third drought stress period (WOY 33) the mean of the STS trunk radial increment decreased and the plants stopped growing altogether in WOY 36. The mean of the LTS trunk radial increment rate instead still increased by $29 \%$ after the third drought stress term (WOY 33 and 34 ) and decreased slowly till the end of the experiment (WOY 41 ), with the minimum weekly values of $0.015 \%$. The effect of the VPD on the mean weekly radial increment measured by dendrometers was more incisive for the STS than the LTS treatments, with a coefficient of correlation of 0.619 and 0.548 , respectively (Figure 6(c)).

Analyzing the mean water use, calculated during various phases of growth, the difference between the LTS and STS decreased from $60 \%$ during the first period (WOY 23 to 27 ) to $7 \%$ during the last period (WOY 35 to 41 ) (Figure 7(a)). The frequency of the drought stress neither significantly affected the mean primary branch radial increment measured with the caliper (Figure 7(b)), nor was a significant difference found between the treatments by normalizing the dataset (Figure 7(c)).

3.3. Root Vertical Distribution and Total Leaf Area. The mean of the total root biomass production was not significantly different between the treatments; however, the LTS mean of the root weight (340.8 g) was 13\% more, compared to the root weight of the STS treatment $(298.4 \mathrm{~g}$ ). For both treatments the mean of the root weight at $5 \mathrm{~cm}$ was significantly different, compared to the mean root weight estimated at 20 and $40 \mathrm{~cm}$ 


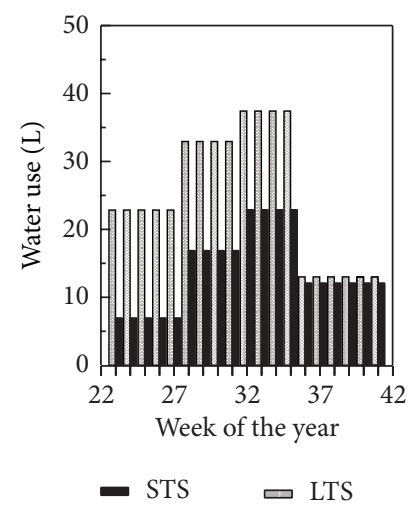

(a)

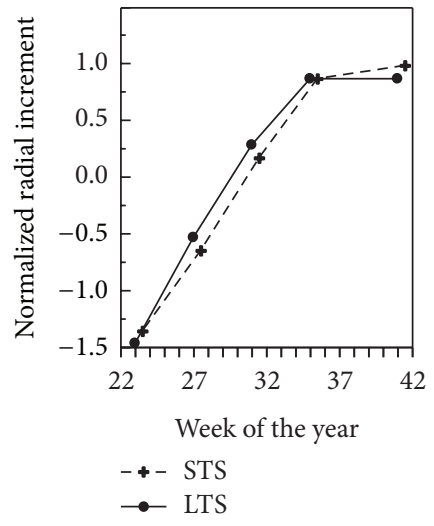

(b)

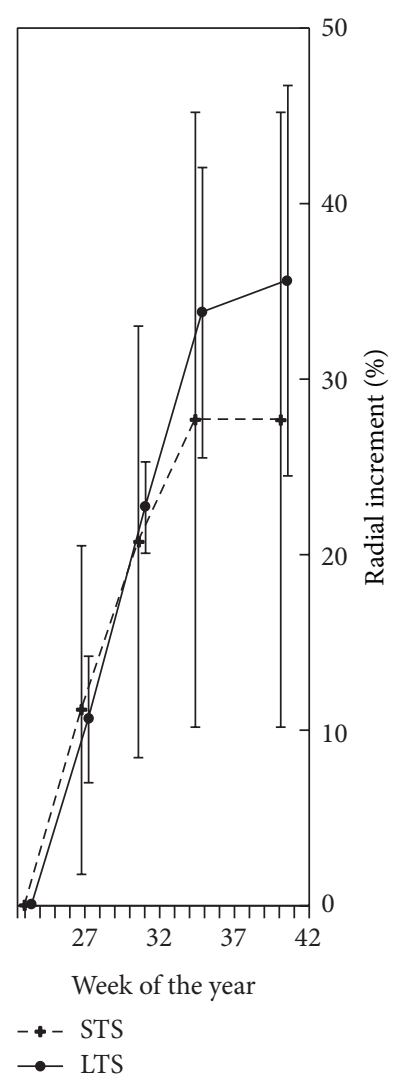

(c)

Figure 7: (a) Mean weekly water use and (b) mean and standard deviation of the primary branches relative radial increments measured with caliper and (c) mean primary branch radial increments normalized, measured with caliper.

depth. The portion of the root developed at $5 \mathrm{~cm}$ depth was $66 \%$ and $74 \%$ of the total, for the STS and LTS treatment, respectively (Figure 8).

Notwithstanding the fact that the difference between the treatments in terms of total leaf area was not significant (Figure 9(a)), the estimated mean of the LTS total leaf area $\left(6.2 \mathrm{~m}^{2}\right)$ was $17 \%$ higher than the mean of the STS total leaf area $\left(5.2 \mathrm{~m}^{2}\right)$. The mean of the ratio root weight: leaf area was significantly different between the treatments, being for STS (33.6) only $31 \%$ compared to the LTS treatment (106.4) (Figure 9(b)).

3.4. Production. The total dry aboveground biomass produced during the vegetation period was comparable between the treatments (Figure 10(a)). However, the mean of the STS dry aboveground biomass amounted to $1141.5 \pm 135.2 \mathrm{~g}$, which was $36 \%$ more than with the LTS production $(730.2 \pm$ $76.6 \mathrm{~g})$. The mean STS dry wood production amounted to $821.4 \pm 39.8 \mathrm{~g}$, which was $44 \%$ higher than the LTS dry wood production $(462.0 \pm 71.1 \mathrm{~g}$ ) (Figure $10(\mathrm{a}))$. The STS treatments produced the higher amount of aboveground biomass, even though its branch radial increment was lower than the one of the LTS. This incongruence is due to

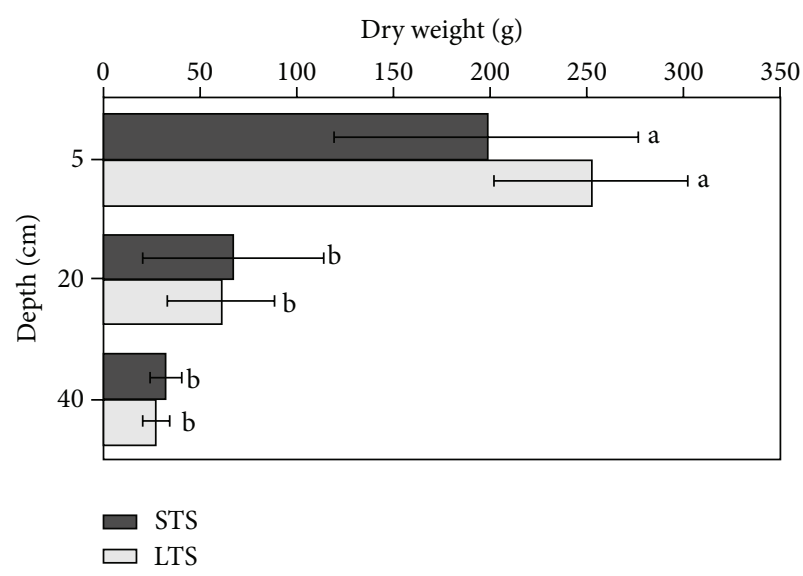

FIGURE 8: Mean and standard deviation of the root weight, at 5, 20, and $40 \mathrm{~cm}$ depth. ${ }^{*}$ Nonparametric analysis Mann-Whitney $U$ test. ${ }^{*}$ Different letters indicate significant difference $(P<0.05)$.

the branch radius dimension of the two treatments. The mean primary branch radius of the LTS at the beginning of the experiment amounted only to $78 \%$ compared to the STS. In terms of a comparable relative growth, we have a more substantial absolute increase of biomass. The leaf: wood ratio was 0.41 for the STS and 0.59 for the LTS treatment. The WUE of the LTS was slightly higher compared to the STS, but the difference was not significant between the treatments (Figure 10(b)).

The coefficient of correlations between water use and dry total biomass (0.997) and water use and dry wood (0.928) was significant. For both the relation is linear; the WUE and the EWUE under drought condition amounted of $2.57 \mathrm{~g} \mathrm{~L}^{-1}$ $\left(r^{2}=0.84\right)$ and $1.79 \mathrm{~g} \mathrm{~L}^{-1}\left(r^{2}=0.99\right)$, respectively (Figure 11$)$.

\section{Discussion}

4.1. Leaf Water Potential and Growth. The severity of the drought stress is tightly related to the soil characteristics, rather than the absolute values of the $\theta$. Therefore, the $\Psi_{L}$ is effective as a drought stress indicator to evaluate the plant sensitivity to the reduction of the soil water availability [24-27]. Unlike indirect methods (e.g., soil moisture or soil matric potential measurements), a plant-based direct method presents the advantage of evaluating the true water status of the plant, rather than the soil conditions. Under the simulated soil moisture conditions in the lysimeter, the tree growth was not influenced by the plant water status, and no noteworthy relation between the mean of the weekly growth increase and the mean of the weekly $\Psi_{L}$ could be found.

4.2. Water Use. Black locust is a ring-porous tree with wide early wood pores and, if watered well, it demonstrates high water consumption, as generally recorded for trees with a comparable hydraulic architecture arrangement [28]. However, black locust demonstrated a high plasticity, since the species can cope with a wide range of environmental conditions $[10,29]$. As the water availability decreases, stomatal 


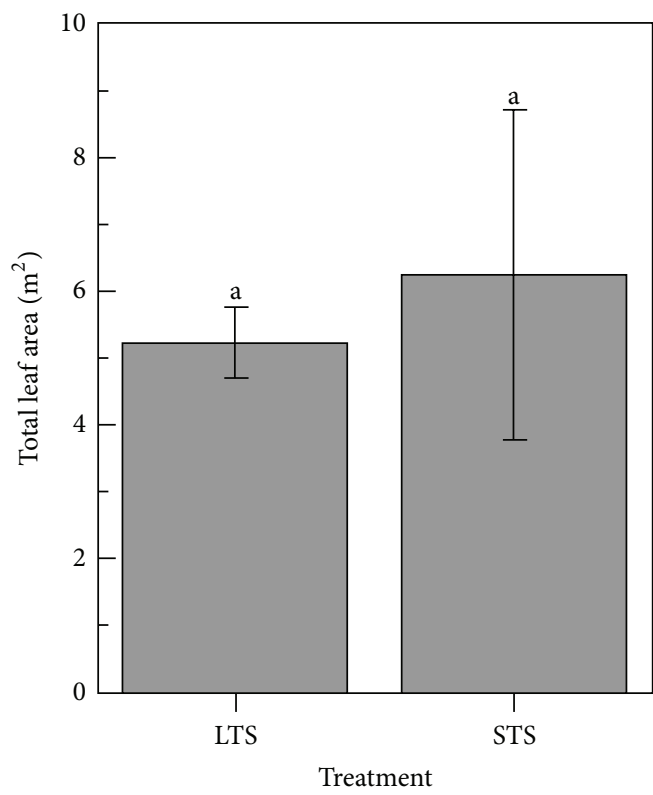

(a)

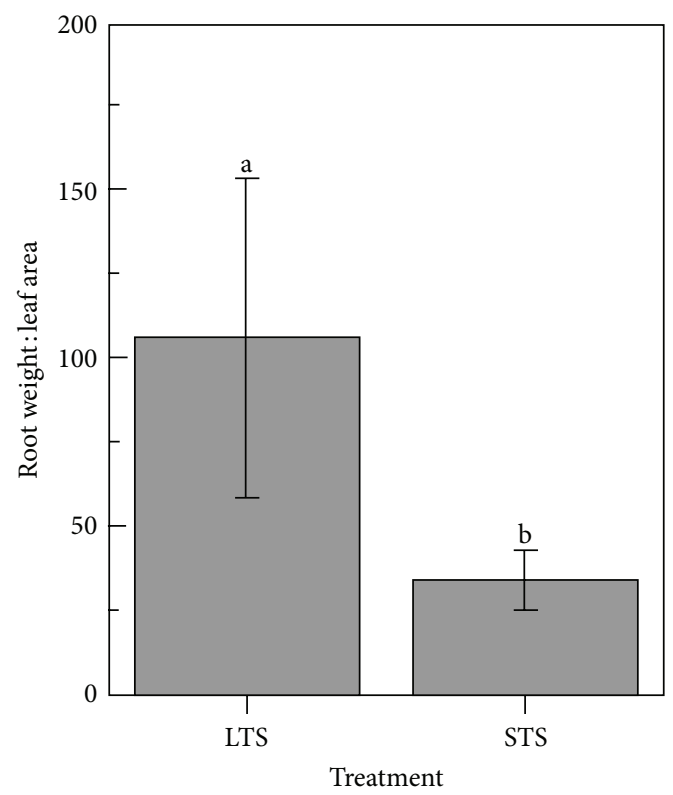

(b)

FIGURE 9: Mean and standard deviation of the (a) total leaf area and (b) root weight:leaf area ratio at 5, 20, and $40 \mathrm{~cm}$ depth. ${ }^{*}$ Non parametric analysis Mann-Whitney $U$-Test. * Different letters indicate significant difference $(p<0.05)$.

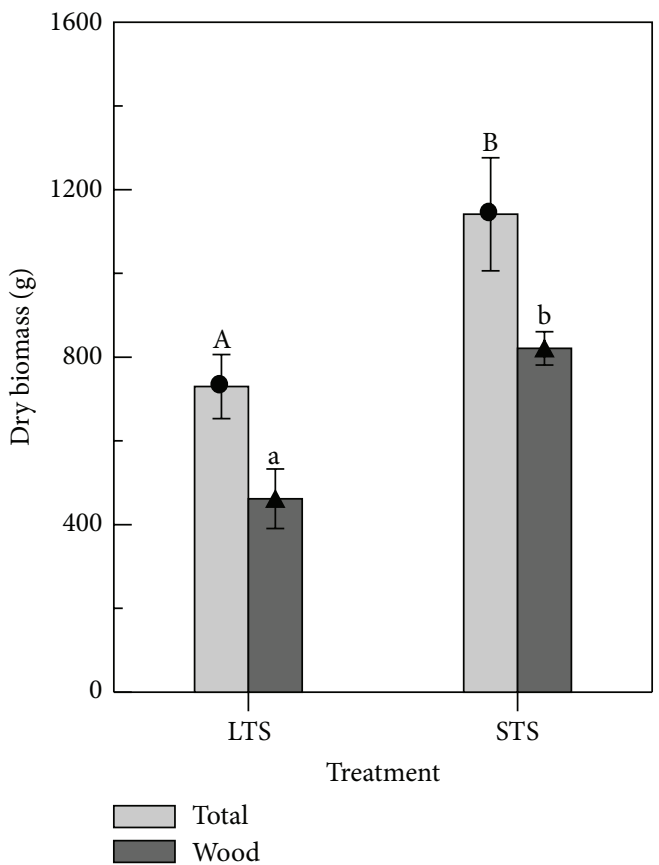

(a)

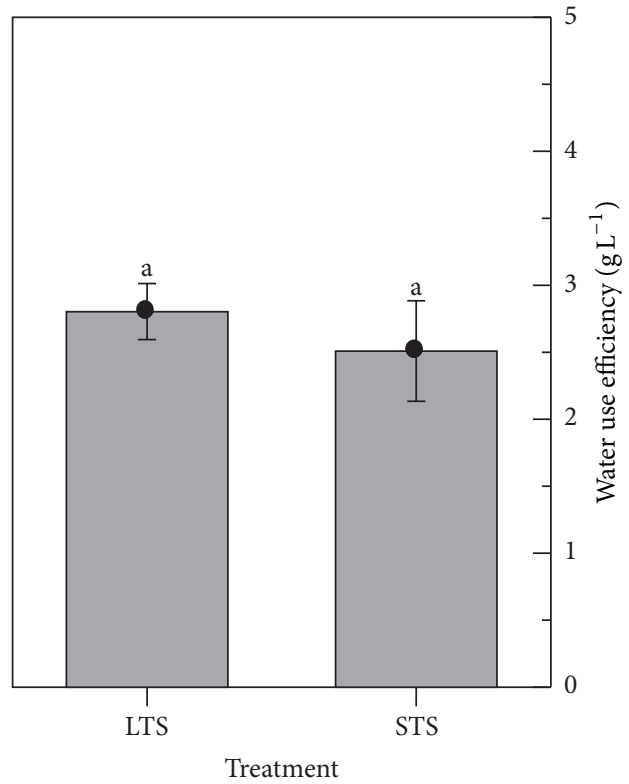

(b)

Figure 10: (a) Mean and standard deviation of the above ground dry total biomass and dry wood biomass produced during the vegetation period; (b) mean and standard deviation of the water use efficiency under different drought stress duration. ${ }^{*}$ Nonparametric analysis MannWhitney $U$ test. * Different letters indicate significant difference $(P<0.05)$. 


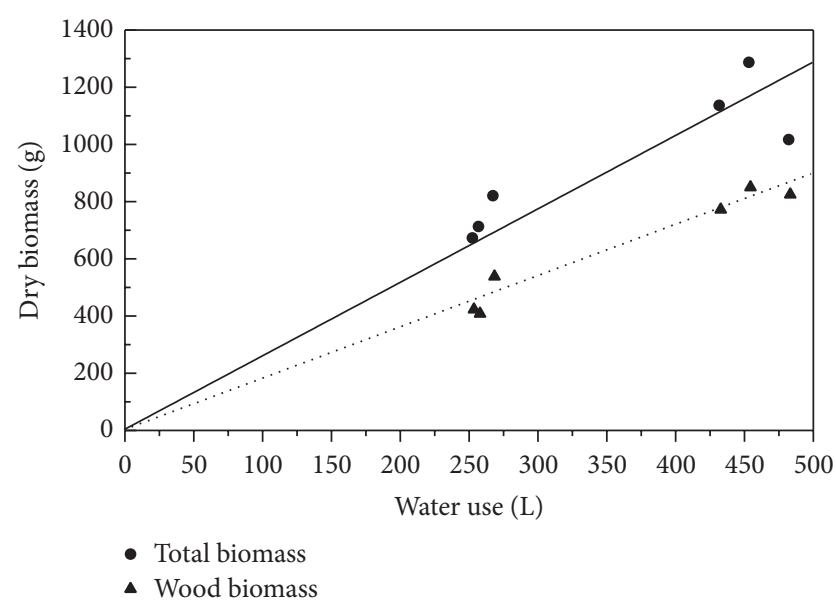

Figure 11: Water use efficiency under different drought stress durations, for the dry wood and the dry total aboveground biomass.

regulation takes place in order to minimize the transpiration at the expense of the photosynthetic carbon gain [30]. If the stress is protracted, physiological adjustments $[13,31$, $32]$ and hydraulic architecture acclimation occur [18-20, 22, 23 ] in order to maintain the functionality of the vascular system [33, 34]. As found in our studies, morphological adaptations occurred in response to the induced drought stress. Due to the lower total leaf area the LTS treatment resulted to be more tolerant to drought stress. A higher ratio root weight: total leaf area calculated for LTS enhanced its efficiency in using the water resources during the drought stress periods. Furthermore, due to the reduction of the total leaf area, its potential transpiration decreased, reducing the water loss during the days with relatively high VPD and limited water availability. As a matter of fact, the LTS plants that resprouted under water constraint after the winter were more tolerant to the imposed drought stress extreme heat conditions in August 2012 than the STS plants. Also for other broad leaf species such as Fagus sylvatica, it has been found that the previous summer drought stress had effects on the transpiration and photosynthesis of the following years and influenced the growth performance [35]. On the other hand, the STS underwent only temporary adjustments to cope with the short-term drought stress applied during the resprouting phase. The plants evidently acclimatized to well-watered conditions in terms of potential transpiring surface, rather than through the xylem hydraulic capacity differentiation [33] demonstrated by the higher water consumption already at the early stages. A larger transpiring leaf surface means higher potential transpiration, which is beneficial only when the water supply is sufficient. However, by reducing the soil water availability or increasing the VPD, stomatal regulation takes place [10], and if the stress persists, a reduction of the transpiring surface occurs to minimize the embolism hazard [36].

4.3. Growth Increment and Biomass Production. The soil water availability reduction at the initial stage of the plant development was revealed to be a critical factor to enhance the ability for recovery after subsequent drought stress, as reported in previous studies [23, 37]. Higher biomass production was characterized by higher water consumption, independent of the growth rate and the drought stress duration. The WUE value of $2.56 \mathrm{~g} \mathrm{~L}^{-1}$ was calculated for black locust under drought stress, this value lying within the same range of the typical values estimated for trees such as Populus and Salix growing in temperate climate zones, namely, between 1.42 and $6.66 \mathrm{~g} \mathrm{~L}^{-1}$ [38-41]. Therefore, the link between the drought stress, transpiration and primary production is clear: independently from the drought stress frequency and duration, the primary production is directly proportional to the water used.

\section{Conclusions}

The experiment emphasized the importance of the combination of preconditions and drought cycles on the drought tolerance of Robinia pseudoacacia L. Prestressed trees have already a lower total leaf area and therefore lower water consumption. Under increased transpiration demands with increasing summer temperature they tolerate the applied drought stress better than the STS with a larger leaf area. In the STS trees the potential water demand is higher than the soil water availability. The water imbalance, in combination with the high temperatures, leads to a drastic leaf fall and fully stops of the growth under such conditions. A more extended root system, together with the reduction of the total leaf area as an adaptive strategy, appears to be effective in order to enhance the drought tolerance of black locust. However, its growth performance is strongly affected by the soil water availability. The initial conditions of resprouting play a central role in defining the recovery processes after drought stress, which is of fundamental importance for the growth performance of black locust on marginal lands at the edges of its distribution area in Central Europe, where water is a limiting factor and summer droughts and temperatures above $30^{\circ} \mathrm{C}$ occur. This has important implication for the management of short-rotation forestry systems. The high plasticity of Robinia and its recovery potential after stress makes the tree species relevant for the production of biomass as raw material in the drier regions of Central and Eastern Europe.

\section{Conflict of Interests}

The authors declare that there is no conflict of interests regarding the publication of this paper.

\section{References}

[1] P. Ciais, M. Reichstein, N. Viovy et al., "Europe-wide reduction in primary productivity caused by the heat and drought in 2003," Nature, vol. 437, no. 7058, pp. 529-533, 2005.

[2] U. Cubasch and C. Kadow, "Global climate change and aspects of regional climate change in the Berlin-Brandenburg region," Erde, vol. 142, no. 1-2, pp. 3-20, 2011.

[3] N. Schaller, I. Mahlstein, J. Cermak, and R. Knutti, "Analyzing precipitation projections: a comparison of different approaches 
to climate model evaluation," Journal of Geophysical Research D: Atmospheres, vol. 116, no. 10, Article ID D10118, pp. 1984-2012, 2011.

[4] A. Holsten, T. Vetter, K. Vohland, and V. Krysanova, "Impact of climate change on soil moisture dynamics in Brandenburg with a focus on nature conservation areas," Ecological Modelling, vol. 220, no. 17, pp. 2076-2087, 2009.

[5] R. Monclus, E. Dreyer, M. Villar et al., "Impact of drought on productivity and water use efficiency in 29 genotypes of Populus deltoides x Populus nigra," New Phytologist, vol. 169, no. 4, pp. 765-777, 2006.

[6] E. Sevigne, C. M. Gasol, F. Brun et al., "Water and energy consumption of Populus spp. bioenergy systems: a case study in Southern Europe," Renewable and Sustainable Energy Reviews, vol. 15, no. 2, pp. 1133-1140, 2011.

[7] R. S. Zalesny, D. M. Donner, D. R. Coyle, and W. L. Headlee, "An approach for siting poplar energy production systems to increase productivity and associated ecosystem services," Forest Ecology and Management, vol. 284, pp. 45-58, 2012.

[8] H. Grünewald, C. Böhm, A. Quinkenstein, P. Grundmann, J. Eberts, and G. von Wühlisch, "Robinia pseudoacacia L.: a lesser known tree species for biomass production," Bioenergy Research, vol. 2, no. 3, pp. 123-133, 2009.

[9] F. Xu, W. Guo, W. Xu, Y. Wei, and R. Wang, "Leaf morphology correlates with water and light availability: what consequences for simple and compound leaves," Progress in Natural Science, vol. 19, no. 12, pp. 1789-1798, 2009.

[10] M. Veste and W. U. Kriebitzsch, "Influence of drought stress on photosynthesis, transpiration, and growth of juvenile black locust (Robinia pseudoacacia L)," Forstarchiv, vol. 84, no. 2, pp. 35-42, 2013.

[11] D. Mantovani, M. Veste, A. Badorreck, and D. Freese, "Evaluation of fast growing tree water use under different soil moisture regimes using wick lysimeters," iForest, vol. 6, pp. 190-200, 2013.

[12] J. Walter, A. Jentsch, C. Beierkuhnlein, and J. Kreyling, "Ecological stress memory and cross stress tolerance in plants in the face of climate extremes," Environmental and Experimental Botany, vol. 94, pp. 3-8, 2012.

[13] H. Lambers, F. S. Chapin III, and T. L. Pons, Plant Physiological Ecology, Springer, New York, NY, USA, 1998.

[14] S. Leuzinger, G. Zotz, R. Asshoff, and C. Körner, "Responses of deciduous forest trees to severe drought in Central Europe," Tree Physiology, vol. 25, no. 6, pp. 641-650, 2005.

[15] N. Bréda, R. Huc, A. Granier, and E. Dreyer, "Temperate forest trees and stands under severe drought: a review of ecophysiological responses, adaptation processes and longterm consequences," Annals of Forest Science, vol. 63, no. 6, pp. 625-644, 2006.

[16] K. J. Bradford and T. C. Hsiao, "Physiological responses to moderate water stress," in Physiological Plant Ecology, O. L. Lange, P. S. Nobel, B. Osmond, and H. Ziegler, Eds., vol. 2, pp. 263-324, Springer, Berlin, Germany, 1982.

[17] H. Cochard, L. Coll, X. Le Roux, and T. Améglio, "Unraveling the effects of plant hydraulics on stomatal closure during water stress in walnut," Plant Physiology, vol. 128, no. 1, pp. 282-290, 2002.

[18] M. T. Tyree and F. W. Ewers, "The hydraulic architecture of trees and other woody plants," New Phytologist, vol. 119, no. 3, pp. 345-360, 1991.

[19] H. Cochard, N. Bréda, A. Granier, and G. Aussenac, "Vulnerability to air embolism of three European oak species (Quercus petraea (Matt) Liebl, Q. pubescens Willd, Q. robur L)," Annales des Sciences Forestières, vol. 49, no. 3, pp. 225-233, 1992.

[20] J. A. Jarbeau, F. W. Ewers, and S. D. Davis, "The mechanism of water-stress-induced embolism in two species of chaparral shrubs," Plant, Cell and Environment, vol. 18, no. 2, pp. 189-196, 1995.

[21] C. Lovisolo and A. Schubert, "Effects of water stress on vessel size and xylem hydraulic conductivity in Vitis vinifera L," Journal of Experimental Botany, vol. 49, no. 321, pp. 693-700, 1998.

[22] M. Pigliucci, Phenotypic Plasticity: Beyond Nature and Nurture, John Hopkins University Press, Baltimore, Md, USA, 2001.

[23] G. S. Newman, M. A. Arthur, and R. N. Muller, "Above- and belowground net primary production in a temperate mixed deciduous forest," Ecosystems, vol. 9, no. 3, pp. 317-329, 2006.

[24] M. Veste, M. Staudinger, and M. Küppers, "Spatial and temporal variability of soil water in drylands: plant water potential as a diagnostic tool," Forestry Studies in China, vol. 10, no. 2, pp. 7480, 2008.

[25] N. Z. Saliendra, J. S. Sperry, and J. P. Comstock, "Influence of leaf water status on stomatal response to humidity, hydraulic conductance, and soil drought in Betula occidentalis," Planta, vol. 196, no. 2, pp. 357-366, 1995.

[26] L. Donovan, M. Linton, and J. Richards, "Predawn plant water potential does not necessarily equilibrate with soil water potential under well-watered conditions," Oecologia, vol. 129, no. 3, pp. 328-335, 2001.

[27] A. Gallé, P. Haldimann, and U. Feller, "Photosynthetic performance and water relations in young pubescent oak (Quercus pubescens) trees during drought stress and recovery," New Phytologist, vol. 174, no. 4, pp. 799-810, 2007.

[28] M. D. Abrams, "Adaptations and responses to drought in Quercus species of North America," Tree Physiology, vol. 7, pp. 227-238, 1990.

[29] F. Xu, W. Guo, R. Wang, W. Xu, N. Du, and Y. Wang, "Leaf movement and photosynthetic plasticity of black locust (Robinia pseudoacacia) alleviate stress under different light and water conditions," Acta Physiologiae Plantarum, vol. 31, no. 3, pp. 553-563, 2009.

[30] J. S. Sperry, "Hydraulic constraints on plant gas exchange," Agricultural and Forest Meteorology, vol. 104, no. 1, pp. 13-23, 2000.

[31] H. J. Bohnert, "What makes desiccation tolerable?" Genome Biology, vol. 1, no. 2, pp. 15-16, 2000.

[32] S. Munné-Bosch and L. Alegre, "Changes in carotenoids, tocopherols and diterpenes during drought and recovery, and the biological significance of chlorophyll loss in Rosmarinus officinalis plants," Planta, vol. 210, no. 6, pp. 925-931, 2000.

[33] D. L. Shumway, K. C. Steiner, and M. D. Abrams, "Effect of drought stress on hydraulic architecture of seedlings from five population of green ash," Canadian Journal of Botany, vol. 69, pp. 2158-2164, 1991.

[34] L. Poorter, I. McDonald, A. Alarcón et al., "The importance of wood traits and hydraulic conductance for the performance and life history strategies of 42 rainforest tree species," New Phytologist, vol. 185, no. 2, pp. 481-492, 2010.

[35] W. U. Kriebitzsch and M. Veste, "Bedeutung trockener Sommer für die Photosynthese und Transpiration von verschiedenen Herkünften der Rot-Buche (Fagus sylvatica L.)," Landbauforsch, vol. 62, no. 4, pp. 193-209, 2012. 
[36] R. Tognetti, A. Longobucco, and A. Raschi, "Vulnerability of xylem to embolism in relation to plant hydraulic resistance in Quercus pubescens and Quercus ilex co-occurring in a Mediterranean coppice stand in central Italy," New Phytologist, vol. 139, no. 3, pp. 437-447, 1998.

[37] T. J. A. Bruce, M. C. Matthes, J. A. Napier, and J. A. Pickett, "Stressful "memories" of plants: evidence and possible mechanisms," Plant Science, vol. 173, no. 6, pp. 603-608, 2007.

[38] H. S. Grip, S. Halldin, A. Lindroth, and G. Persson, "Evapotranspiration from a willow stand on wetland," Ecology and Management of Forest Biomass Production Systems, vol. 15, pp. 47-61, 1984.

[39] A. Lindroth, T. Verwijst, and S. Halldin, "Water-use efficiency of willow: variation with season, humidity and biomass allocation," Journal of Hydrology, vol. 156, no. 1-4, pp. 1-19, 1994.

[40] C. Yin, X. Wang, B. Duan, J. Luo, and C. Li, "Early growth, dry matter allocation and water use efficiency of two sympatric Populus species as affected by water stress," Environmental and Experimental Botany, vol. 53, no. 3, pp. 315-322, 2005.

[41] Z.-S. Liang, J.-W. Yang, H.-B. Shao, and R.-L. Han, "Investigation on water consumption characteristics and water use efficiency of poplar under soil water deficits on the Loess Plateau," Colloids and Surfaces B: Biointerfaces, vol. 53, no. 1, pp. 23-28, 2006. 

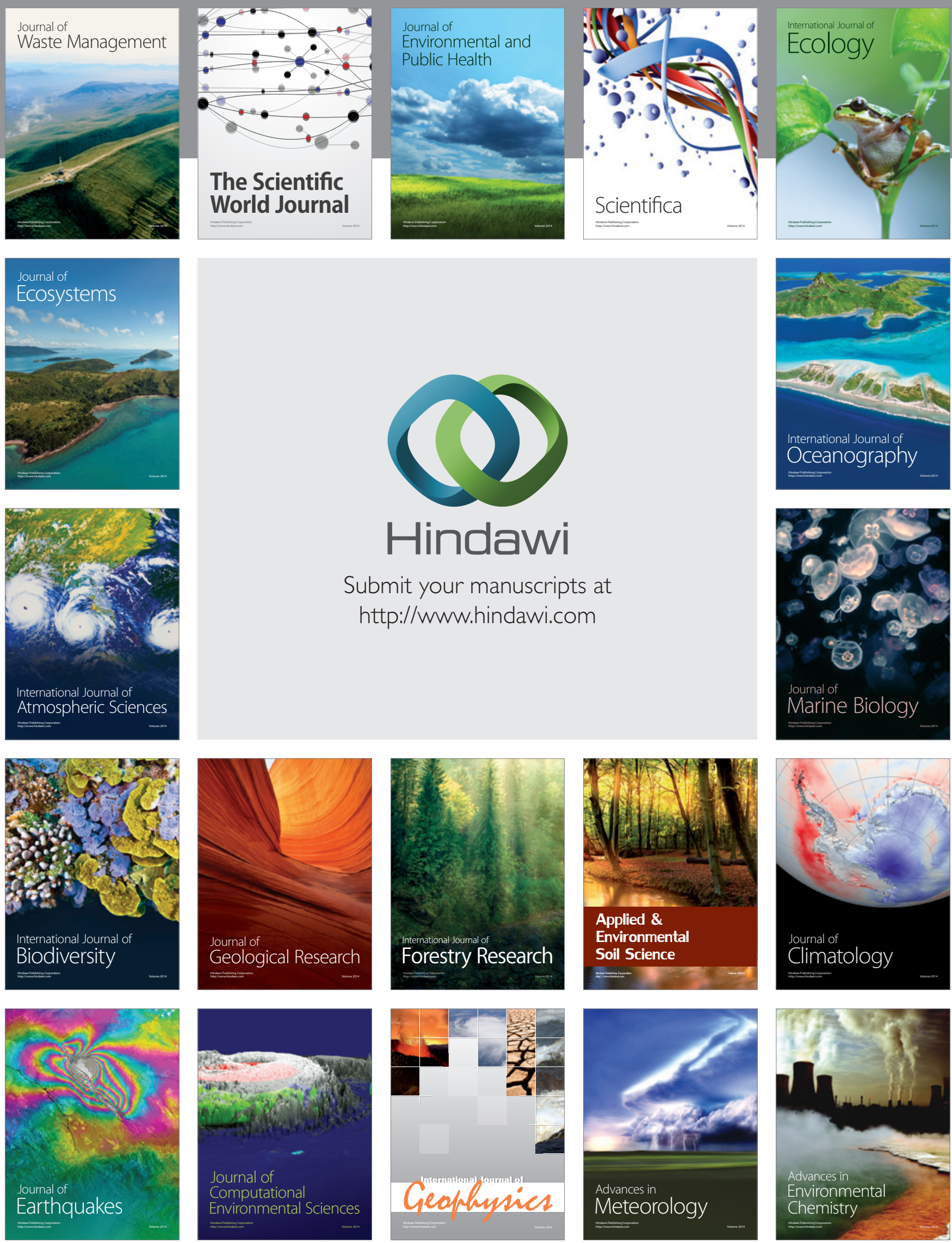